\title{
TINJAUAN TENTANG TUGAS DAN PERAN RECEPTIONIST PADA PT. DSSP POWER MAS UTAMA DI JAKARTA
}

\author{
Sugiyarto \\ Dosen Prodi D-III Sekretari Universitas Pamulang \\ email :dosen01722@unpam.ac.id \\ Andriani Miraza \\ Mahasiswi Sekretari Universitas Pamulang
}

\begin{abstract}
ABSTRAK
Pelayanan sangatlah penting, dalam menunjang keberhasilan sebuah perusahaan. Oleh karena itu, peran dan tugas seorang receptionist secara professional sangat di butuhkan. Receptionist sebagai ujung tombak perusahaan bisa menjadi agen perusahaan dalam memberikan informasi kepada pelanggan dan supplier perusahaan sehingga tercipta hubungan yang saling menguntungkan diantara kedua belah pihak. Seorang receptionist juga menuntut penampilan yang selalu rapi, murah senyum dan menarik.
\end{abstract}

Kata Kunci : Pelayanan, Receptionist

\section{PENDAHULUAN}

\section{Latar Belakang Masalah}

Receptionist atau penerima tamu sangat berperan penting dalam perusahaan, karena dengan melihat pelayanan awal yang di berikan seorang receptionist maka pelanggan akan memiliki gambaran seperti apa perusahann tersebut. Seorang receptionist harus memiliki kampuan menangani para tamu yang datang dan memiliki kemampuan dalam membuat skala prioritas terkait dengan kepentingan tamu perusahaan dan yang tidak kalah penting adalah apakah tamu tersebut sudah membuat janji atau belum harus jelas. Receptionist di tuntut memiliki kemampuan dalam menangani pekerjaan yang dilimpahkan kepada dirinya secara baik dengan penuh tanggung jawab.

Secara langsung pekerjaan dan attitude seorang receptionist akan membawa pengaruh terhadap image perusahaan menuju ke arah yang baik atau sebaliknya. Hal ini tergantung sikap mental seorang receptionist untuk melayani tamu perusahaan. 
Dengan latar belakang tersebut dan untuk mengetahui lebih jauh bagaimana peranan receptionist dalam perusahaan maka penulis memilih judul "Tinjauan Tentang Tugas dan Peran Receptionist pada PT. DSSP Power Mas Utama di Jakarta".

\section{Identifikasi Masalah}

Berdasarkan Latar Belakang Masalah Tinjauan Tentang Tugas dan Peran Receptionist pada PT. DSSP Power Mas Utama, diidentifikasikan masalah antara lain:

1. Banyak masyarakat yang belum mengetahui tugas dan peran receptionist.

2. Banyak masyarakat yang belum mengetahui tanggung jawab seorang receptionist.

3. Banyak masyarakat belum mengetahui syarat menjadi seorang receptionist

4. Receptionist belum paham cara melayani tamu.

5. Receptionist beluam mengetahui karakter tamu yang dihadapi

\section{Pembatasan Masalah}

Waktu penelitian yang sangat singkat serta keterbatasan tenaga, maka penulis membatasi masalah sesuai dengan pengetahuan yang didapat selama melaksanakan Praktik Kerja Lapangan di PT. DSSP Power Mas Utama. Maka penulis membuat laporan mengenai tugas akhir pada "Tinjauan Tentang Tugas dan Peran Receptionist pada "PT. DSSP Power Mas Utama di Jakarta".

\section{Rumusan Masalah}

Berdasarkan latar belakang, identifikasi dan pembatasan masalah maka dirumuskan masalah yang berhubungan dengan Tinjauan Tugas dan Peran Receptionist pada PT. DSSP Power Mas Utama adalah sebagai berikut:

1. Apa saja tugas dan peran receptionist dalam suatu perusahaan ?

2. Apakah tanggung jawab seorang receptionist ?

3. Bagaimana sikap seorang receptionist kepada tamu ?

4. Bagaimana cara menyelesaikan keluhan tamu ?

\section{Tujuan dan Manfaat Penulisan}

\section{Tujuan Penulisan}

a. Untuk mengetahui sejauh mana tugas dan peran receptionist dalam perusahaan 
b. Untuk mengetahui bagaiamana cara receptionist dalam membuat nyaman pelanggan yang complain terhadap perusahaan

\section{Manfaat Penulisan}

Berikut ini adalah beberapa manfaat yang dapat diambil dari penulisan ini :

1. Bagi Penulis

Sebagai bentuk penerapan ilmu yang di pelajari terkait dengan pelayanan prima terhadap pelanggan, dan untuk menambah wawasan dan meningkatkan kemampuan untuk menjadi receptionist profesional dalam dunia kerja .

2. Bagi Perusahaan

Sebagai informasi tambahan bagi perusahaan terkait dengan karakter pelanggan apa yang menjadi harapan pelanggan dan supplier terhadap perusahaan melalui informasi dan komunikasi yang di titipkan kepada receptionist perusahaan. Mendapatkan masukan untuk meningkatkan kinerja perusahaan. Membantu proses kinerja perusahaan.

\section{LANDASAN TEORI}

\section{Pengertian Receptionist}

Receptionist adalah seseorang yang bertugas sebagai penerima tamu di suatu perusahaan, hotel atau kantor, Pengertian menurut Kamus Besar Bahasa Indonesia (1996:837). Dan pengertian lainnya menurut para ahli yaitu:

1. Receptionist atau Front Office adalah suatu pekerjaan yang sifatnya tulis-menulis dan bekerja dikantor belakang. (Sugiarto). 2004:2).

2. Receptionist adalah pegawai yang bertugas khusus menerima dan melayani tamu. (Wursanto). 1993:76).

Menurut kesimpulan, Receptionist adalah seseorang yang bertugas menerima dan melayani tamu. Profesi ini juga membantu sekretaris untuk meringankan tugas-tugas di kantor

\section{Kepribadian Receptionist}


Paul B. White dan Helen Beckley (1973:6) dalam bukunya Kantor Reception, menyatakan bahwa kepribadian atau personality mempunyai makna sebagai berikut:

\section{$\mathbf{P}=$ Pleasantess}

Goodmanners and a smile are natural assets. (Seorang resepsionis kantor diharapkan mampu menyenangkan para tamu melalui kesopan- santunan disertai senyum yang ramah. Hal ini merupakan suatu aset yang tidak pernah habis dalam suatu kantor).

\section{$\mathrm{E}=$ Eagerness}

Eagerness to help others, with a liking for people and a willingness to serve them. (Seorang resepsionis kantor harus mempunyai keinginan kuat yang timbul dari dalam dirinya untuk membantu para tamu dan rela melayani tamu dengan menyuguhkan pelayanan yang PRIMA. Hal ini merupakan salah satu unsur kepribadian).

\section{$\mathrm{R}=$ Respect}

Respect for other people. Coutesy costs nothing (Seorang resepsionis kantor harus memahami bahwa melayani, menghormati dan menghargai tamu sangatlah penting. Bersopan santun dan ramah tamah terhadap semua tamu tidak membutuhkan biaya).

\section{$\mathrm{S}=$ Sense of responsibility}

Sense of responsibility is a realisation that what one does and says is important (Memiliki rasa tanggung jawab terhadap pekerjaan merupakan sebuah realisasi bahwa apa yang resepsionis lakukan dan katakana kepada para tamu adalah penting).

\section{$\mathrm{O}=$ Orderly mind}

Essential for methodical and accurate work.

(Seorang resepsionis harus memilki pola pikir yang teratur dan terarah dalam melakukan pekerjaan dengan metode yang baik dan akurat).

\section{$\mathbf{N}=$ Neatness}

Neatness indicates pride in self and job.

(Seorang resepsionis harus rapi dan bersih menunjukkan bahwa dirinya bangga dengan pekerjaannya ).

\section{A = Accuracy}

Accuracy in everything done is of paramount importance.

(Seorang resepsionis yang teliti dalam melakukan setiap pekerjaan merupakan suatu nilai yang sangat penting).

\section{$\mathrm{L}=$ Loyality}


Loyality to management and colleagnes makes good team work.

(Seorang resepsionis dituntut untuk mewakili sikap setia/loyal kepada manajemen kantor dan rekan kerjanya. Karena kerja sama tim yang tangguh merupakan kunci keberhasilan setiap pekerjaan).

\section{I = Intelegence}

Intelegence of common sense at all times.

(Seorang resepsionis harus menggunakan pola pikir positif dalam melayani tamu). $\mathbf{T}=$ Tact

Tact saying and doing the right thing at the right time. (Mengatakan sesuatu dengan bijaksana serta melakukan segala sesuatu secara benar saat melakukan pekerjaan merupakan ciri kepribadian yang kuat).

\section{Y=Yearning to be good receptionist}

A love of the work is essential. (Untuk menjadi resepsionis yang baik harus timbul keinginan untuk mencintai pekerjaan tersebut).

\section{Tugas dan peran Receptionist}

Berikut ini adalah tugas dan tanggung jawab receptionist menurut Sutiyoso dalam Wursanto (2006:18) adalah sebagai berikut:

1. Menyambut tamu yang datang

2. Menerima panggilan telepon masuk dan keluar

3. Menangani surat, dokumen, dan paket yang datang

Disamping tugas utama seperti yang telah disebutkan receptionist juga memiliki tugas ringan lainnya, seperti:

1. Receptionist bertugas membantu sekretaris

2. Receptionist bertugas membantu kegiatan administrasi HRD

Macam-macam tamu yang dihadapi receptionist :

1. Tamu datang dengan perjanjian terlebih dahulu

2. Tamu datang tanpa perjanjian terlebih dahulu 
Jenis tamu yang dapat diterima oleh pimpinan, biasanya tamu sudah buat janji terlebih dahulu, tamu teman pimpinan, tamu internal (pegawai kantor sendiri), pejabat pemerintah, tamu aparat pemerintah/yang berwenang digolongkan menjadi bersifat kunjungan rutin, bersifat kunjungan khusus.

\section{Peralatan Kerja Receptionist}

1. Telephone

2. Mesin Facimile yang di gunaka untuk mengirim dan menerima dokumen

3. Mesin foto copy dan Scanner

Scanner adalah sebuah alat pemindai salah satu perangkat input pada komputer, merupakan suatu alat yang berfungsi untuk menduplikat objek layaknya seperti mesin fotokopy ke dalam bentuk digital

4. Mesin Printer

Printer adalah peranti yang menampilkan data dalam bentuk cetakan, baik berupa teks maupun gambar/grafik, di atas kertas

5. Komputer

Komputer adalah perangkat elektronik yang memanipulasi informasi atau data. Komputer mampu menyimpan, mengambil, dan mengolah data.

6. Outner sebagai tempat untuk menyimpan dokumen sesuai dengan kalsifikasinya.

\section{HASIL DAN PEMBAHASAN}

\section{Sejarah Singkat Perusahaan}

PT. DSSP Power pertama kali beroperasi pada tanggal 1 Januari 1998, dengan 4 pembangkit listrik yang berada di wilayah Tangerang, Serang, dan Karawang. Pada tahun 2011 didirikan PT. DSSP Power Sumsel (IPP Sumsel-5 project) dengan kapasitas 2x150 MW, kemudian pada tahun 2015 didirikan PT. DSSP Power Kendari (PLTU Kendari-3) dengan kapasitas 2x50 MW. Dan pada tahun 2016 didirikan IPP Kalteng-1 project dengan kapasitas 2x100 MW1.

Visi : Becoming a leading energy and insfrastructure company in Indonesia.

( Menjadi perusahaan energi dan insfrastruktur terkemuka di Indonesia ).

Misi : Creating Sustainable growth for our business by providing the right solutions for our 
customers.

( Menciptakan pertumbuhan yang berkelanjutan untuk bisnis kami dengan menyediakan solusi yang tepat bagi pelanggan kami ).

\section{Tugas dan Peran Receptionist PT. DSSP Power Mas Utama}

1. Menerima tamu yang datang

2. Menerima panggilan telepon masuk dan keluar.

3. Menangani surat, dokumen, dan paket yang datang

4. Berperan untuk menyaring arus informasi

5. Berperan sebagai pusat informasi

\section{Tanggung Jawab receptionist PT. DSSP Power Mas Utama}

1. Memastikan bahwa area lobby dan ruang tunggu selalu dalam keadaan rapih, bersih dan wangi serta lampu penerangan harus selalu menyala apabila ada yang putus segera beritahu kepada bagian yang menanganinya. Pastikan tamu yang datang selalu merasa nyaman. Receptionist harus memberikan perhatian lebih terhadap tamu yang datang seperti menawarkan minum, menyiapakan bacaan diruang tunggu dan memberikan informasi keberadaan toilet apabila tamu ingin ke toilet.

2. Mengurus ruang meeting

Selain melayani tamu, receptionist juga bertugas mengurus dan menghandle ruang meeting serta mengatur book ruangan meeting. Pihak internal yang ingin memakai ruangan meeting, terlebih dahulu booked kepada receptionist.

Didalam book ruang meeting nantinya berisikan:
a. Nama yang booked ruangan
b. Waktu (hari/tanggal/jam)
c. Keterangan meeting dengan siapa

3. Menjaga perlengkapan kantor

Receptionist diharapkan dapat menjaga, memelihara, dan memantau perlengkapan kantor serta memberikan laporan apa saja yang sudah tidak ada stok atau sudah habis. Alat tulis kantor harus dimanfaatkan dengan baik dan catatan arsip harus dijaga. 


\section{Pelayanan Receptionist Terhadap Tamu}

Receptionist berperan langsung terhadap tamu yang datang, maka yang pertama harus dilakukan adalah pelayanan terhadap tamu tersebut. Pelayanan yang baik tentu mencerminkan nama baik perusahaan. sebagai seorang receptionist dalam melayani tamu perlu memperhatikan hal-hal sebagai berikut:

1. Sambut dengan salam, ramah, senyum hangat, dan sikap bersahabat tetap menghormati tamu.

2. Biasakan berdiri ketika menyambut tamu yang datang.

3. Menanyakan nama, darimana dan keperluannya apa dengan sopan dan santun.

4. Jika harus menunggu arahkan ke ruang tunggu dan berikan tamu tersebut minuman.

5. Jika harus langsung ke ruang meeting maka arahkan tamu tersebut kedalam ruang meeting, tidak lupa untuk membuka kan pintu ruang meeting.

6. Jika sedang menerima telepon, receptionist cukup tersenyum dan memberi arahan mempersilahkan tamu duduk terlebih dahulu dan menunggu hingga pembicaraan di telepon selesai.

7. Receptionist harus menggunakan intonasi nada suara yang rendah dan tidak terlalu tinggi mencerminkan kesan ramah dan menghormati.

\section{PENUTUP}

\section{Kesimpulan}

Pelayanan sangatlah penting, dalam menunjang keberhasilan sebuah perusahaan. Oleh karena itu, peran dan tugas seorang receptionist di suatu perusahaan sangatlah penting karena receptionist merupakan ujung tombak perusahaan. Dimana keberhasilan suatu perusahaan tidak akan terlepas dari pelanggan/tamu. Receptionist adalah seseorang yang bertugas untuk menangani tamu yang datang ke perusahaan.

Berdasarkan hasil praktek kerja dan pembahasan yang telah diuraikan maka dibuat kesimpulan sebagai berikut: 
1. Dengan perkembangan zaman yang semakin maju akan membuat persaingan semakin ketat, maka perusahaan dituntut untuk memberikan pelayanan terbaik kepada setiap tamu yang datang. Dalam sebuah perusahaan diperlukan receptionist, yang memiliki peran dan tugas yaitu menerima dan melayani para tamu yang datang ke perusahaan.

2. Seorang receptionist harus mampu memberikan pelayanan terbaik kepada setiap tamu yang datang ke perusahaan. Oleh karena itu, receptionist dituntut untuk memiliki rasa tanggung jawab atas pekerjaannya, terampil, terdidik dan dapat memberikan pelayanan terbaik.

3. Sebagai seorang receptionist harus mengetahui dan memiliki sikap-sikap yang baik dalam melayani tamu yang datang, harus mampu memberikan kesan profesional, sopan santun, ramah, menyenangkan, dan beretika baik, sekaligus dapat memberikan keuntungan bagi perusahaan.

\section{Saran}

Adapun saran yang dapat penulis berikan untuk menunjang pelayanan receptionist pada PT. DSSP Power Mas Utama adalah sebagai berikut:

1. Dalam menyelesaikan tugas dan peran sebagai seorang receptionist perlunya pengetahuan lebih yang harus diketahui oleh receptionist, maka perlunya pelatihan yang wajib perusahaan adakan untuk receptionist.

2. Pentingnya tanggung jawab seorang receptionist untuk perusahaan, mempunyai feed back tersendiri dari perusahaan seperti belajar dalam berbahasa asing contohnya bahasa Inggris dan Mandarin yang telah dikenal sebagai bahasa internasional. Agar receptionist dapat memahami lebih dalam berbahasa, dan tentunya menguntungkan juga untuk perusahaan agar terjalin komunikasi yang baik terhadap orang.

\section{DAFTAR PUSTAKA}

\section{Buku :}

Kamus Besar Bahasa Indonesia Edisi ke-2, Departemen Pendidikan dan Kebudayaan, Balai Pustaka, Jakarta, 1996. 
Lawalata, C.F.Ch, "Panduan Lengkap Pekerjaan Sekretaris", Jakarta : Akademia Permata, 2012.

Sudarwanto, Rig Heru, Et. All, "Paket Keahlian Sekretaris 3”, PT. Galaxy Puspa Mega, Bekasi, 2002.

Sugiarto, Endar, “Hotel Front Office Administration”, Jakarta : Gramedia Pustaka Utama,2004.

Webster, Merriam, “Merriam-Webster's Collegiate Dictionary”, $11^{\text {th }}$ Edition, 2003

White, Paul B and Beckley, Helen. “Kantor Reception”, London, 1973.

Wursanto IG, Drs, “Dasar-Dasar Ilmu Tata Usaha”, Jakarta, 1993.

Wursanto, Ignatius, “Kompetensi Sekretaris Profesional”, Yogyakarta : Andi Offset, 2006.

\section{Website :}

https://silvislippi25.wordpress.com/2013/12/16/menjadi-resepsionis-yang-baik/

(Tanggal akses 13 Maret 2018).

https://kesekertarisan12.blogspot.co.id/2012/10/hal-hal-yang-perlu-diperhatikan.html

(Tanggal akses 13 Maret 2018).

https://www.dosenpendidikan.com/telepon-pengertian-cara-kerja-jenis-keuntungan-

kekurangan/ (Tanggal akses 14 Maret 2018).

https://id.wikipedia.org/wiki/Faksimile (Tanggal akses 14 Maret 2018).

https://id.wikipedia.org/wiki/mesin_fotocopy (Tanggal akses 14 Maret 2018).

https://www.pengertianku.net/2015/02/pengertian-scanner-dan-fungsinya-dilengkapi-carakerjanya.html (Tanggal akses 14 Maret 2018). 